\title{
A Multiple Case Study of Sustainability Issues in Companies from Sugar and Ethanol Industrial Sector
}

\author{
Eduardo Satolo \\ Methodist University of Piracicaba (UNIMEP), Santa Bárbara d' Oeste, SP, Brazil
}

Felipe Araujo Calarge

University Nine of July (UNINOVE), São Paulo, SP, Brazil

Paulo Augusto Cauchick Miguel

Federal University of Santa Catarina (UFSC), Campus Trindade, Florianópolis, SC, Brazil

\begin{abstract}
The sugar cane and ethanol agricultural industrial sector has emerged as one of the most prominent industrial sectors in developing countries like Brazil. Sustainability issues are now more and more important and companies from this sector have been structured their operations to achieve positive results. One of the ways of doing that is by implementing an integrated quality and environmental management system. In this context, this paper aims at identifying the relevant practices related to integrated management systems in four organizations that belong to the sugar cane and ethanol industrial sector. Data were gathered through a questionnaire and semi-structured interviews. The paper highlights relevant issues in policy of the four units. An individual case description is made in addition to a cross-case comparison. As a result, an analysis of management systems in those units enables to raise important issues on how the studied companies take care of their environment economically and with their use for continuous improvement. Finally, the evidence shows a general concern for the environment although this is demonstrated by a culture of reducing residuals and the control of waste of natural resources.
\end{abstract}

Keywords: Integrated management system, IMS, Sustainability, Sugar cane and ethanol.

\section{Introduction}

The sugar cane and ethanol agricultural industrial sector has emerged as one of the most prominent industrial sectors in developing countries like Brazil, both in the domestic and international markets. Brazil is one of the world's largest sugar and ethanol exporters, a market with many growth opportunities. In fact, until 2006, the country was the world's main producer. Since then, the US has assumed the leading position. Nevertheless, Brazil's ethanol production is expected to triple by 2020 . As a result, there has been a lot of discussion about how to recapture the lead either in terms of technological or managerial issues.

Sustainability is another important aspect added to this current discussion. The traditional concept of sustainability involves three fundamental assumptions. The first is that businesses have an interest in generating value in the long term. The second 
is that business conduct, which is destructive to the natural or social environment, will ultimately give rise to burdensome direct and indirect costs - either through the imposition of formal penalties imposed by governments or through the loss of value in damaged relationships with key stakeholders including: customers, current and future employees, shareholders, and so on. Finally, it is argued that the pursuit of sustainable growth creates new commercial opportunities for businesses that are able to develop and market new goods and services that help to achieve the goals of sustainability (Longstaff, 2002).

Currently, this concept has become more widespread. Sustainable development has three dimensions (Fresner and Engelhardt, 2004): social, ecological, and economic, and a number of issues need to be considered with regard to quality, the environment, and occupational health and safety. Standardized management systems, such as ISO 9000 for quality management and ISO 14000 (2004) for the environmental management, have become a widespread phenomenon all over the world (Jonker and Karapetrovic, 2004). The global number of ISO 9001 and ISO 14001 certifications are now over 1 million and 220 thousand (ISO, 2009), respectively. As those systems and others (e.g., OHSAS 18001 for health and safety and SA 8000 for social accountability) have a lot in common (Fresner and Engelhardt, 2004), a dominant current trend is toward integration (Jorgensen et al., 2006). Integrating systems has emerged as one of the major tasks for practicing managers (Karapetrovic and Willborn, 1998). The integration of such management systems may reduce costs and redundancies (Beckmerhagen et al., 2003) and synergy among the management systems can be realized (Fresner and Engelhardt, 2004).

It is imperative that the companies develop and implement an integrated management system - IMS (Beckmerhagen et al., 2003). In doing so, the companies centralize their efforts and resources in one system instead of having separate systems for quality, environmental, health and safety system, and so on. Beckmerhagen et al. (2003) add that there is evidence in the literature and practice that organizations are slowly starting to tackle the IMS issue, mainly by putting an integrated quality and environmental management system in place. Moreover, an international standard covering integration methodologies does not currently exist. At the national level, different countries have developed guidelines for integration, for example (Bernardo et al., 2009): in Australia and New Zealand (AS/NZS 4581: 1999), in Denmark (DS 8001: 2005), in Spain (UNE 66177: 2005), and in the United Kingdom (PAS 99: 2006). Therefore, is relevant for the companies to establish an integrated management system in order to optimized resources on management systems.

In this context, this paper aims at demonstrating the results of an investigation whose objective it is to identify relevant practices related to an integrated management system in an organization that belongs to the sugar cane and ethanol agricultural industrial sector. More specifically, it assesses sustainability issues in the context of an IMS. The work was conducted in the state of São Paulo, Brazil, in a highly industrialized region that produces sugar and ethanol. Case-based research was used as the methodological approach, grounded in the literature presented next.

\section{Literature Review}

The concept of integration is understood from different points of view and is examined in the literature by several authors (Wilkinson and Dale, 1999, 2001; Zutsi 
and Sohal, 2005; Jorgensen et al., 2006). For the purpose of this paper, the concept of integration is understood as a combination of several common or inter-related elements of the management systems aiming at the greater effectiveness of overall management. Integration involves more than just adding elements of systems that have been structured by experts (Fresner and Engelhardt, 2004) and cannot be defined as putting different systems into a unique manual (Wilkinson and Dale, 1999).

A genuinely integrated system is one that combines management systems using an employee focus, a process view, and a systems approach that makes it possible to put all the relevant management standard practices into a single system (Pojasek, 2006). The integration of different management systems is related to quality, environment, and health and safety (Wilkinson and Dale, 1999) and more recently associated with social responsibility (Jorgensen et al., 2006). The literature points out that various approaches to the integration of management systems have emerged. An integrated management systems form a kind of 'system of the systems' (Wilkinson and Dale, 1999), having the objective of using the existing synergies between those standards/systems during the development and implementation of a managerial system (Mackau, 2003). Basically, an IMS involves systems that are based on ISO 9001, ISO 14001, OHSAS 18001, and SA 8000 standards, and they are summarized as follows.

\section{ISO 9001: 2008 - Quality Management System}

ISO 9001 can be regarded as one of the most successful standards that has been deployed around the world having as its main objective to develop a quality management system for the organizations. The first release was issued in 1987 as a quality assurance system and in 1994 its first revision was carried out. In this version, the quality assurance system had 3 sub-standards (ISO 9001, ISO 9002, and ISO 9003) that were applied according to the scopes of the organizations. Since then, there have been 2 versions to replace the 1994 version, one in 2000 and the 2008 version, which is presented as ISO 9001:2008 and has as its main, explicit goals: improve effectiveness via process performance metrics; continuous process improvement and customer satisfaction. The ISO 9001:2008 defines a set of quality management system requirements that are listed in the following elements: Quality management system (clause 4); Management responsibility (clause 5); Resource management (clause 6); Product realization (clause 7) and Measurement, analysis and improvement (clause 8) (ISO, 2008). The standard requires from the organization an internal procedure in order to develop the documentation needed in order to demonstrate the planning, operation, and control of its processes and the implementation, and continuous improvement of the effectiveness of its Quality Management System (Naveh and Marcus, 2005).

\section{ISO 14001 - Environmental Management Systems}

ISO 14000 is a series of international standards on environmental management, was first published in September 1996, amended in November 2004, and the main thrust for its development came as a result of the Rio Summit on the Environment held in 1992. It provides a framework for the development of an environmental management system (Lagodimos et al., 2007). The standard is meant for any organization that wants to achieve the following: establish, implement, maintain, and improve an environmental management system; assure itself of conformity with 
its stated environmental policy and demonstrate conformity with this international standard. The requirements of ISO 14001 (2004) is a management tool enabling an organization of any size or type to: identify and control the environmental impact of its activities, products, or services; improve its environmental performance continually; implement a systematic approach to setting environmental objectives and targets, to achieving these and to demonstrating that they have been achieved (ISO, 2010). During the implementation process of ISO 14001, some key points that must be observed are (Zutshi and Sohal, 2004): environmental policy, planning, implementation, operation stages; inspection and corrective actions; management oversight.

\section{OHSAS 18001: Occupation Health and Safety Assessment Series}

An occupational health and safety management system (OHSAS) is used to establish an $\mathrm{OH} \& \mathrm{~S}$ policy and to manage $\mathrm{OH} \& \mathrm{~S}$ risks, being composed by interrelated elements that include responsibilities, authorities, relationships, functions, activities, processes, practices, procedures, and resources. OHSAS 18001 (BSI, 2007) is an occupational health and safety standard that is used to establish your occupational health $\&$ safety management system, and even though it is not recognized as a standard by ISO (International Organization for Standardization), it is internationally recognized by most organizations in terms of third-party certification. This standard emerged in 1996 as BS 8800 - Guide to Occupational Health and Safety Management System. In 1999 was updated and released under the title OHSAS 18001, being the first internationally recognized assessment specification for occupational health and safety management systems (Zeng et al., 2007). The process of revising OHSAS 18001 started in 2005, and the version OHSAS 18001 standard was published on July 2007. The new version is more results oriented than the previous version and it is better aligned with the ISO 9001 and ISO 14001 standards. OHSAS 18001 defines a set of occupational health and safety management system requirements that are listed in the following elements (OHSAS 18001: 2007, 2010): General requirements (4.1); OH\&S policy \& commitment (4.2); Planning (4.3); Hazard identification, risk assessment/control (4.3.1); Legal and other requirements (4.3.2); Objectives (4.3.3); OH\&S management program(s) (4.3.4); Implementation and operation (4.4); Structure and responsibility (4.4.1); Training, awareness, and competence (4.4.2); Consultation and communication (4.4.3); Documentation (4.4.4); Document and data control (4.4.5); Operational control (4.4.6); Emergency preparedness and response (4.4.7); Checking and corrective action (4.5); Performance measurement and monitoring (4.5.1); Accidents, incidents, non-conformances and corrective and preventive action (4.5.2); Records and records management (4.5.3); Audit (4.5.4); Management review (4.6).

\section{Social Accountability 8000 - SA 8000}

SA 8000 is an international certification standard that enables organizations to develop, maintain, and apply socially acceptable practices, becoming the first global standard to ensure the sourcing and production of goods and services. It has been developed based on the conventions of the International Labor Organization, the Universal Declaration of Human Rights, as well as the United Nations Convention on the Rights of a Child, being applicable to companies regardless of the economic sector, scale, and location (SAI, 2010). It was created in 1989 by Social Accountability 
International (SAI, 2008), an affiliate of the Council on Economic Priorities, and is viewed as the most globally accepted independent standard in the areas that address child labor (element 1); forced labor (element 2); health and safety (element 3); freedom of association and collective bargaining (element 4); discrimination (element 5); disciplinary practices (element 6); working hours (element 7); compensation (element 8 ) and management systems (element 9). It is possible, however, for other specifically designed systems to be part of the IMS, such as (Karapetrovic, 2002): aerospace (AS 9100), automotive (ISO TS 16949), ergonomics, and telecommunications (TL 9000). Even with some experiences in implementing different quality management systems and a growing number of academic publications, practitioners are still facing difficulties in the process of introducing such systems in addition to deriving benefits (Zutshi and Sohal, 2004). An overview of the literature and an examination of the concept of integration are provided by Wilkinson and Dale (2002). Table 1 presents a summary of some publications on integrated management systems.

Table 1. IMS Literature.

\begin{tabular}{|c|c|}
\hline General Objective & References \\
\hline $\begin{array}{c}\text { Discusses quality (ISO 9001) and environmental (ISO 14001) } \\
\text { management system integration by providing strategies to achieve } \\
\text { integration }\end{array}$ & $\begin{array}{l}\text { Karapetrovic and } \\
\text { Willborn (1998) }\end{array}$ \\
\hline $\begin{array}{l}\text { Presents a literature review of integrated management systems dealing } \\
\text { with quality, environmental, and health and safety management }\end{array}$ & $\begin{array}{l}\text { Wilkinson and Dale } \\
\text { (1999) }\end{array}$ \\
\hline $\begin{array}{c}\text { Proposes a theoretical model based on empirical research that provides } \\
\text { details of a integrated management system that considers the dimensions } \\
\text { of quality, environmental, and occupational health and safety } \\
\text { management }\end{array}$ & $\begin{array}{l}\text { Wilkinson and Dale } \\
\qquad(2001)\end{array}$ \\
\hline $\begin{array}{l}\text { Discusses issues for the development of an integrated management } \\
\text { system in addition to supporting audit methodologies. }\end{array}$ & Karapetrovic (2002) \\
\hline $\begin{array}{l}\text { Focuses on the integration of a safety management system within an } \\
\text { integrated management system in the nuclear industry }\end{array}$ & $\begin{array}{l}\text { Beckmerhagen et al. } \\
\text { (2003) }\end{array}$ \\
\hline $\begin{array}{l}\text { Provides a summary of the most important issues regarding integrated } \\
\text { management systems, including the main problem, the reasons behind } \\
\text { it, the differentiating routes toward a solution, and the meaning of the } \\
\text { solution itself }\end{array}$ & Karapetrovic (2003) \\
\hline $\begin{array}{l}\text { Analyses two case studies that demonstrate integration of the } \\
\text { environmental, quality, health, and safety dimensions in two small } \\
\text { companies in Australia }\end{array}$ & $\begin{array}{l}\text { Fresner and Engelhardt } \\
\qquad(2004)\end{array}$ \\
\hline $\begin{array}{c}\text { Discusses how a systems approach to management can be used } \\
\text { to facilitate the development and implementation of an integrated } \\
\text { management systems and provide a set of criteria for selecting the most } \\
\text { appropriate IMS model }\end{array}$ & $\begin{array}{c}\text { Jonker and } \\
\text { Karapetrovic (2004) }\end{array}$ \\
\hline $\begin{array}{l}\text { Presents the experiences of three organizations in Australia that } \\
\text { undertook the integration of their management systems for quality, } \\
\text { environmental, and occupational health and safety }\end{array}$ & $\begin{array}{l}\text { Zutshi and Sohal } \\
\qquad \text { (2004) }\end{array}$ \\
\hline $\begin{array}{l}\text { Discusses three different levels of integration considering ISO 9001, } \\
\text { ISO 14001, OHSAS } 180001 \text {, and SA } 8000 \text { and a proposal for national } \\
\text { IMS standards in Denmark and Spain }\end{array}$ & Jorgensen et al. (2006) \\
\hline
\end{tabular}


In considering an investigation of IMS in the sugar cane and ethanol agricultural industrial sector as relevant, this paper conducts a study on one of the biggest sugar cane and ethanol organizations in Latin America, whose research methods are described next.

\section{Research Methods}

The methodological research approach for this work can be categorized as case-based research. Guidelines in the existing literature (Yin, 1994; Cauchick Miguel, 2007) were followed for data collection and analysis. The steps that were carried out for conducting the case study were (Cauchick Miguel, 2007): (i) define a theoretical structure; (ii) plan the cases; (iii) collect data; (iv) analyze data; (v) generate a report. Case selection was limited to companies located in the state of São Paulo in Brazil. The rationale is based on a government survey (CONAB, 2006) that identified 370 organizations that produce sugar and ethanol. The results of that survey indicated that the companies in the state of São Paulo are the most prominent in the industrial sector. Table 2 shows the importance of production in the state of São Paulo.

Table 2 shows that the number of organizations in the state of São Paulo (SP) is relevant as well as production. Moreover, nearly one third of firms have more than a half of production (sugar and ethanol). A general profile of companies is shown in Table 3.

Table 2. Comparison between the State of São Paulo (SP) and Brazil (BR).

\begin{tabular}{|c|c|c|c|}
\hline Measure & BR & SP & Ratio (\%) \\
\hline Number of organizations & 437 & 182 & 41.65 \\
\hline Number of companies in construction & 21 & 6 & 28.57 \\
\hline Area planted with sugar cane (million hectares) & 9.9 & 5.15 & 52.02 \\
\hline Average productivity (tons per hectare) & 69.1 & 52.2 & - \\
\hline Sugar production (million tons) & 31.05 & 19.60 & 63.12 \\
\hline Ethanol production (billion liters) & 25.10 & 16.70 & 66.53 \\
\hline Jobs (in thousands) & $\sim 1.000$ & $\sim 400$ & - \\
\hline
\end{tabular}

Source: data from UNICA (2010).

Table 3. Characteristics of the companies.

\begin{tabular}{|c|c|c|c|c|}
\hline Characteristics & Unit A & Unit B & Unit C & Unit D \\
\hline City & Piracicaba & Rio das Pedras & Tietê & Cerquilho \\
\hline Cane production* & $4,180,869$ & $1,021,346$ & 442,052 & $1,039,447$ \\
\hline Sugar cane production (t)* & 311,705 & 107,698 & 36,206 & 76,439 \\
\hline Ethanol production (million liters)* & 167,396 & 15,272 & 16,358 & 60,120 \\
\hline Ranking (sugar production in the country) & 11 & 34 & 121 & 98 \\
\hline Ranking ethanol production in the country & 24 & 174 & 154 & 113 \\
\hline
\end{tabular}

*Source: Data from UNICA (2010). 
As can be seen in Table 3, companies vary from large to medium plants in terms of production or ranking in the country. Nevertheless, all of them may be considered relevant for the present study. The management systems adopted by the units are shown in Table 4. As can be seen in the table the integrated management systems are different among the units.

A questionnaire was developed and sent to the companies to collect data concerning their IMS. It was based on the literature on IMS (e.g. Table 1). It comprised three sections: (i) characterization of the interviewee, (ii) characterization of the company, and (iii) the assessment of the level of sustainability of the unit of analysis. The characterization of the interviewee consists of his/her position in the company, department, amount of experience time, and contact details. The second section involved company data such as year of foundation, number of employees, types of product, main customers, market share, annual sales and some aspects of its production. The third section is regard to the main topic of research (integrated management system) as well as aspects of sustainability.

Twelve questions considered the following issues relevant to integrating the management systems: company policy; objectives, goals, programs; awareness and training; document control, assessment and monitoring, complaint management, preventive and corrective actions; internal auditing; and critical analysis. Those issues were assessed by a company respondent using a scale from 1 to 10 ( 1 - 'not realized at all' to 10 - 'totally realized'). Three prior pilot applications of the questionnaire were done to enhance the instrument in both format and content. Some criteria for selecting respondents were used, e.g.: experience, education (preferably a graduate degree), professional relationship to the production management and/or quality management system. After sending the questionnaire, semi-structured interviews were conducted with the company quality manager to clarify some points of the questionnaire that were doubtful. Other sources of evidence were used (e.g., document analysis) when available. This allowed a triangulation of the sources of evidence in the data content analysis in some parts of the study.

\section{Results}

The assessment results of the organizational sustainability in the units are summarized in Figure 1. The elements in Figure 1 have been extracted from the literature and have a direct or indirect relation with an integrated management system. This section firstly describes the individual results from each unit and then presents a summary comparing them.

Table 4. Management systems in the companies.

\begin{tabular}{|c|c|c|c|c|}
\hline Characteristics & Unit A & Unit B & Unit C & Unit D \\
\hline ISO 9001 & $\mathrm{X}$ & & $\mathrm{X}$ & $\mathrm{X}$ \\
\hline ISO 14001 & $\mathrm{X}$ & & & $\mathrm{X}$ \\
\hline OHSAS 18000 & $\mathrm{X}$ & $\mathrm{X}$ & & \\
\hline SA 8000 & $\mathrm{X}$ & & & \\
\hline ISO 22000 & & $\mathrm{X}$ & & \\
\hline
\end{tabular}



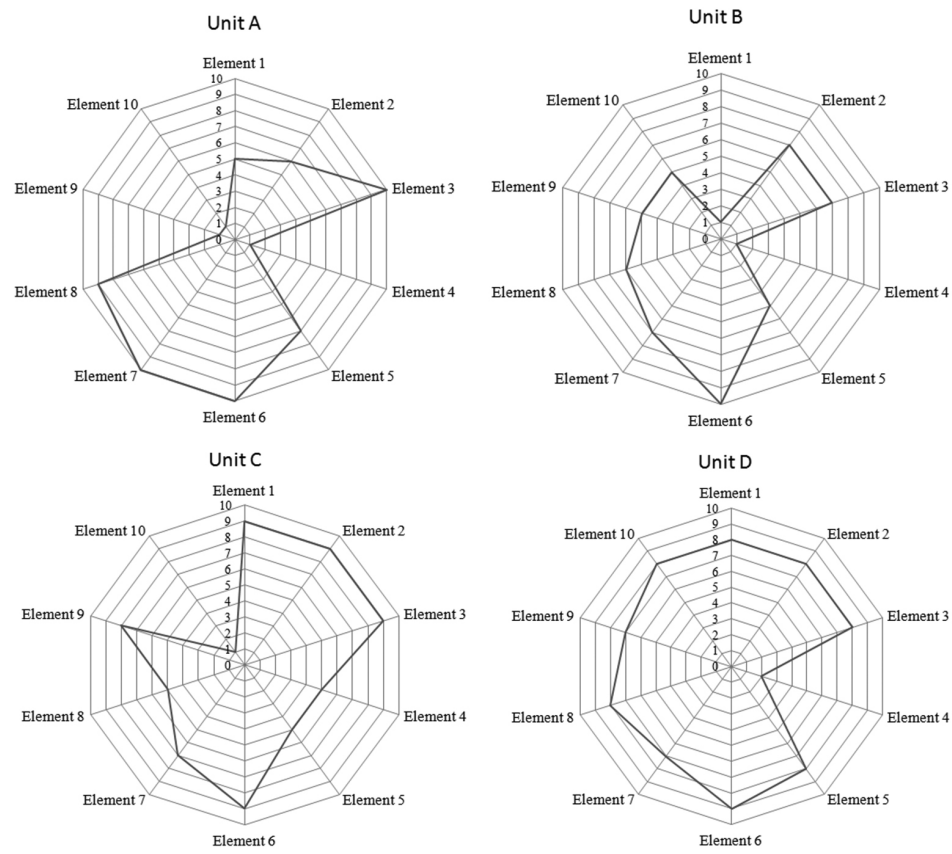

Element 1 - The strategy for growth and product development takes into account the problems related to global
warming
Element 2 - There is a commitment to social, environmental, and economic causes related to the planet
maintenance and its resources in the future
Element 3 - The company has a culture of reducing residues and controlling the natural resources waste
Element 4 - The company publishes a report on the organizational performance in an open, objective, and
organized way
Element 5 - Senior managers follow the feedback from the public and are committed to its implementation
Element 6 - There is either an area or a person responsible for matters related to social responsibility,
environment, and safety and occupational health
Element 7 - There is a structured policy of socio-environmental responsibility and respective actions
Element 8 - There is a management system for receiving and recording complaints or demands from the
stakeholders (either in a direct or indirect way) as a consequence of company operations, products, or services
Element 9 - The goals defined by the company follow a risk management plan, which considers short, medium,
and long-term socio-environmental aspects
Element 10 - The company manages how its operations might be affected by either climate variations, behavior
of the community within which it operates, and occurrences related to its actions, and it may adapt to those risks
- including the financial implications

Figure 1. Sustainability Assessment of the four Units.

\section{Unit A}

The unit A was founded in 1936, with 4,000 employees and a total installed capacity for grinding 24,000 tons of sugar cane, producing 41,500 sugar sacks, and 1,250 thousand liters of alcohol daily. The company has 19 producing units, two refineries, and two harbor distribution terminals, besides for the three industrial units being built. Concerning the process of producing ethanol, the company implemented the technology of molecular sieves, allowing the production of anhydrous ethanol without the need for using the dehydrator cycle-hexane, allowing the production of a purer, non-polluting 
product. In terms of measures for the productive performance, the organization shows growth on the sugar and ethanol production in past years.

\section{Evaluation of the Organizational Sustainability in Unit A}

The assessment for this unit shows that the evaluated elements are applied in its production environment as for elements $3,6,7$, and 8 . Those elements point out that there is a company policy that concerns the environment, employees, and society. This can be demonstrated by the IMS in place, which is formalized and participative. The interviewee highlighted some relevant issues in the company policy: commitment to customer satisfaction, pollution prevention and control, and safety practices; growing with responsibility and sustainability; integrity with regard to comply with legislation and other requirements; and continuous improvement of management systems. The system considers a number of aspects such as those related to social (e.g. educational programs for children and teenagers) and environmental actions (e.g. selective garbage collection, air and water preservation, and reforestation). The elements 1, 2, and 5, however, are in an intermediary position. This demonstrates that a number of aspects must be improved in order to reach corporate sustainability. The starting point is the company's strategic planning and the (lack of) senior management commitment to sustainable growth. Managers should promote strategies and develop products that take into consideration global warming. Otherwise, the commitment to sustainable development will not be achieved. The results from elements 4, 9, and 10 illustrate that. There is no report, related to organizational sustainability, as to how the company operations affect the community is not assessed, and there are no goals that consider a risk management plan. Overall, the company demonstrates that it does not forecast its future activities.

\section{Unit B}

This unit was founded in 1953 and is within the main producers in the region with 500 employees. Besides the production of alcohol and sugar it also commercializes 'melaço' (a residual material with no sugar that can be used as feed for cattle or can be used as a raw material for products such as glycerin, synthetic rubber, and others). The main customers are food companies (e.g. Ajinomoto) and fuel distributors (e.g. Ipiranga). The studied company also has in place a food safety system based on HACCP (hazard analysis and critical control points, which is a systematic preventive approach to food safety and pharmaceutical safety that addresses the physical, chemical, and biological hazards as a means of prevention rather than finished product inspection).

\section{Evaluation of the Organizational Sustainability in Unit B}

Overall, this unit has a medium sustainability level. Most elements in the self-assessment are positioned at an intermediary grade (see Figure 1). This was also confirmed by the interviewee who stated that there is large room for improvement. Moreover, it mentioned that the only fully fulfilled element is the fact that there is a person in charge of environmental matters, social responsibility, as well as occupational health and safety. 
Nevertheless, Figure 1 shows some sustainability practices for the elements $2,3,5,7,8,9$, and 10 . Among those practices are: the company and senior manager's commitment to social and environmental responsibility. Examples are a partnership with the Brazilian Association of Toy Producers (ABRINQ) to supporting children's rights, alphabetization programs, improvement of the quality of life of sugar cane workers, reforesting, as well as residuals and waste management programs, etc. The company has, however, elements in which the assessment is relatively poor ( 1 and 4 ). The former is creating a company policy and the relations with the environment and the latter is how the company publically reports its results and actions of its management system. Those elements concern company strategic planning that will permit the company to consolidate sustainability within its processes.

\section{Unit C}

This unit was founded in 1958 and nowadays has 150 employees. Eighty percent of its production is for the domestic market (sugar and ethanol), mostly food companies and trading companies that export commodities. Currently, it is implementing its management system.

\section{Evaluation of the Organizational Sustainability in Unit C}

As can be seen in Figure 1, there is a wide range of variation in the results of the assessment of unit C. Elements 1, 2, 3, 6, and 9 are realized almost totally. Among those elements, there is a concern with regard to global warming that is taken into consideration within its strategic planning (element 1). This is also confirmed in the interview concerning element 9 . The interviewee stated that the company has a management plan that takes into consideration the socio-environmental aspects for the short and long term. The company also counts on a department that is responsible for issues related to social responsibility, environment, and occupational health and safety. This department is in charge of managing those actions that minimize waste and residual generation. A number of social and environmental programs are in place such as housing for cane sugar workers, dentistry assistance, reforesting with a plantation of 7,000 native and fruit trees.

Other elements such as $4,5,7$, and 8 are also considered in this unit, although with less intensity. Nevertheless, direct observation in a site visit showed that the middle and senior managers are supporting sustainable activities and initiatives. This support is based on a structured policy. There is also a system to receive and record complaints and demands from different stakeholders. All company results are described in a company report of sustainable practices. Nevertheless, it was observed that the company does not take risk planning in its operations as well as does not evaluate how its activities can affect the environment within which it operates. Therefore, the data show that there are opportunities of improvement in unit $\mathrm{C}$.

\section{Unit D}

This unit $\mathrm{C}$ was founded in 1953 and currently has 300 employees. Its production capacity is 9,000 sugar bags and $340 \mathrm{~m}^{3}$ of ethanol per day. The company has an integrated management system in the final phase of implementation. This IMS integrates an ISO 9001: 2008 quality system and an environmental system (voluntary) based on an agribusiness protocol for companies that produce sugar and ethanol. 


\section{Evaluation of the Organizational Sustainability in Unit D}

This unit presented a high level of sustainability in the assessment, as can be seen in Figure 1. This assessment was confirmed by the interview with the person in charge of the company IMS as well as site observations. Therefore, a culture towards sustainability was observed. This was not assessed and came from qualitative data gathered in both the interview as well as in the site visit. However, there is an exception. It concerns the element 4 , relatively to the report results of sustainable company actions. Actually, the company does not report such results.

\section{Cross Comparison}

Table 5 summarizes the results for each element. When analyzing the results from Table 5, elements 6,3, and 7 obtained the best results from the units. Companies have a department to take care of practices for environmental and social responsibility

Table 5. Comparison among the companies.

\begin{tabular}{|c|c|c|c|c|}
\hline Element & Unit A & Unit B & Unit C & Unit D \\
\hline $\begin{array}{c}\text { 1) The strategy for growth and product development takes } \\
\text { into account the problems related to global warming }\end{array}$ & 5 & 1 & 9 & 8 \\
\hline $\begin{array}{c}\text { 2) There is a commitment to social, environmental, and } \\
\text { economic causes related to environmental protection and } \\
\text { natural resources in the future }\end{array}$ & 6 & 7 & 9 & 8 \\
\hline $\begin{array}{c}\text { 3) The company has a culture of reducing residues and } \\
\text { controlling natural resources waste }\end{array}$ & 10 & 7 & 9 & 8 \\
\hline $\begin{array}{c}\text { 4) The company publishes a report on the organizational } \\
\text { performance in an open, objective, and organized way }\end{array}$ & 1 & 1 & 5 & 2 \\
\hline $\begin{array}{c}\text { 5) Senior managers receive feedback from the public and } \\
\text { are committed to its implementation }\end{array}$ & 7 & 5 & 5 & 8 \\
\hline $\begin{array}{c}\text { 6) There is either an area or a person responsible for } \\
\text { matters related to social responsibility, environment, and } \\
\text { safety and occupational health }\end{array}$ & 10 & 10 & 9 & 9 \\
\hline $\begin{array}{c}\text { 7) There is a structured policy of socio-environmental } \\
\text { responsibility and respective actions }\end{array}$ & 10 & 7 & 7 & 7 \\
\hline $\begin{array}{c}\text { 8) There is a management system for receiving and } \\
\text { recording complaints or demands from the stakeholders } \\
\text { (either in a direct or indirect way) as a consequence of } \\
\text { company operations, products, or services }\end{array}$ & 9 & 6 & 5 & 8 \\
\hline $\begin{array}{c}\text { 9) The goals defined by the company follow a risk } \\
\text { management plan, which considers short, medium, and } \\
\text { long-term socio-environmental aspects }\end{array}$ & 1 & 5 & 8 & 7 \\
\hline $\begin{array}{c}\text { 10) The company manages how its operations may be } \\
\text { affected by either climate variations, behavior of the } \\
\text { community within which it operates or occurrences related } \\
\text { to its actions and it may adapt to those risks - including the } \\
\text { financial implications }\end{array}$ & 1 & 5 & 1 & 8 \\
\hline $\begin{array}{c}\text { Sum up } \\
\text { (1) }\end{array}$ & 60 & 54 & 67 & 73 \\
\hline
\end{tabular}


practices and they also have a structured policy toward sustainability. Moreover, they demonstrated their concern for the environment with actions of waste control of natural resources and reducing residuals. Those actions are confirmed by interviews and direct observation.

Conversely, the elements 4 and 10 are those with low grade. Those are concerned with the publication of reports on the performance of their management systems. Moreover, it also considers how their operations can be affected by climate changes, community behavior, and risk planning, including financial aspects of it. This may demonstrate that although there are actions towards sustainability, they are not published publically. Furthermore, the actions taken by the companies are not globally evaluated.

\section{Conclusions}

The assessment of management systems associated with sustainability enables the raising of important issues on how the studied companies take care of their environment economically and with the use of the principles of continuous improvement. It can be concluded that unit D is the one with best level of sustainable practices, followed by units $\mathrm{C}$ and $\mathrm{A}$. Nevertheless, the grades are in an intermediate range so that there is room for improvement.

In an individual analysis of the self-assessment, it is possible to conclude that the companies have a functional area in addition to a corporate policy to protect the environment, support social responsibility, and ensure occupational and health safety. In addition, the evidence shows a general concern for the environment as demonstrated by a culture of reducing residuals and the control of waste of natural resources. Nevertheless, they usually do not publish their results adequately. Moreover, they do not use tools to measure the impact that their operations may have with regard to other issues, such as climate changes, community behavior, and risk analysis. Those are issues to be addressed in future research.

\section{Acknowledgements}

The authors acknowledge the cooperation of the companies where the study was conducted. Nevertheless, this paper only reflects the view of the authors, and not the official view of the companies. The authors would also like to express their gratitude to the CNPq (The Brazilian National Research Council) and CAPES for their financial support for this research project. Finally, the authors thank the reviewers for their comments to improve the paper.

\section{References}

Beckmerhagen, I.A.; Berg, H.P.; Karapetrovic, S.V. and Willborn, W.O. (2003) Integration of management systems: focus on safety in the nuclear industry. International Journal of Quality \& Reliability Management, Vol. 20, No. 2, pp. 210-228. http://dx.doi. org/10.1108/02656710310456626

Bernardo, M.; Casadesus, M.; Karapetrovic, S. and Heras, I. (2009) How integrated are environmental, quality and other standardized management systems? An empirical study. Journal of Cleaner Production, Vol. 17, No. 8, pp. 742-750. http://dx.doi.org/10.1016/j. jclepro.2008.11.003 
Brazilian Sugarcane Industry Association - UNICA. (2010) Sugar Cane Industry Association Report. Available: http://english.unica.com.br/. Access: 14th April 2009.

British Standard Institution - BSI. (2007) OHSAS18001: 2000: Occupational health and safety management systems - specification. London: BSI.

Cauchick Miguel, P.A. (2007) Recommendations for Conducting Case Study in Production Engineering. Produção, Vol. 17, No. 1, pp. 216-229. (in Portuguese).

Companhia Nacional de Abastecimento - CONAB. (2006). Available: http://www. conab.gov.br/conabweb. Access: 14th April 2009.

Fresner, J. and Engelhardt, G. (2004) Experiences with integrated management systems for to small companies in Austria. Journal of Cleaner Production, Vol. 12, No. 6, pp. 623631. http://dx.doi.org/10.1016/j.jclepro.2003.09.013

International Organisation for Standardisation - ISO. (2008) ISO 9001: 2008: Quality Management system. Requirements. Geneva: ISO.

International Organisation for Standardisation - ISO. (2004) ISO 14001: 2004: Environmental management system. Requirements with guidance for use. Geneva: ISO.

International Organisation for Standardisation - ISO. (2009) The ISO Survey - 2009. Geneva: ISO.

International Organization for Standardization - ISO (2010). The ISO Survey - 2010. Geneva: ISO.

Jonker, J. and Karapetrovic, S. (2004) Systems thinking for the integration of management systems. Business Process Management Journal, Vol. 10, No. 6, pp. 608-615. http:// dx.doi.org/10.1108/14637150410567839

Jorgensen, T.H.; Remmen, A. and Mellado, M.D. (2006) Integrated management systems - three different levels of integration. Journal of Cleaner Production, Vol. 14, No. 8, pp. 713-722. http://dx.doi.org/10.1016/j.jclepro.2005.04.005

Karapetrovic, S. (2002) Strategies for the integration of management systems and standards. The TQM Magazine, Vol. 14, No. 1, pp. 61-67. http://dx.doi. org/10.1108/09544780210414254

Karapetrovic, S. (2003) Musings on integrated management systems. Measuring Business Excellence, Vol. 7, No. 1, pp. 4-13. http://dx.doi.org/10.1108/13683040310466681

Karapetrovic, S. and Willborn, W. (1998) Integration of quality and environmental management systems. The TQM Magazine, Vol. 10, No. 3, pp. 204-213. http://dx.doi. org/10.1108/09544789810214800

Lagodimos, A.G.; Chountalas, P.T. and Chatzi, K. (2007) The state of ISO 14001 certification in Greece. Journal of Cleaner Production, Vol. 15, pp. 1743-1754. http://dx.doi. org/10.1016/j.jclepro.2006.06.015

No. 2.

Longstaff, S. (2002) The concept of sustainability. EcoFutures Magazine, Vol. 1,

Mackau, D. (2003) SME Integrated management system: a proposed experiences model. TQM Magazine, Vol. 15, No. 1, pp. 43-51. http://dx.doi.org/10.1108/09544780310454448

Naveh, E. and Marcus, A. (2005) Achieving competitive advantage through implementing a replicable management standard: installing and using ISO 9000. Journal of Operations Management, Vol. 24, pp. 1-26. http://dx.doi.org/10.1016/j.jom.2005.01.004

Pojasek, R. (2006) Is your integrated management system really integrated? Environmental Quality Management, Vol. 16, No. 2, pp. 89-97. http://dx.doi.org/10.1002/ tqem. 20124 
Social Accountability International - SAI. (2010) SA8000 Certified Facilities. Available at: http://www.saasaccreditation.org/certfacilitieslist.htm. Accessed: 12 December, 2009.

Social Accountability International - SAI. (2008) BS 8000. New York: SAI.

Wilkinson, G. and Dale, B.G. (1999) Integrated management systems: an examination of the concept and theory. TQM Magazine, Vol. 11, No. 2, pp. 95-104. http://dx.doi. org/10.1108/09544789910257280

Wilkinson, G. and Dale, B.G. (2001) Integrated management systems: a model based on a total quality approach. Managing Service Quality, Vol. 11, No. 5, pp. 318-330. http://dx.doi. org/10.1108/09604520110404040

Wilkinson, G. and Dale, B.G. (2002) An examination of the ISO 9001:2000 standard and its influence on the integration of management systems. Production Planning and Control, Vol. 13, No.3, pp. 284-297.

Yin, R.R.K. (1994) Case Study Research - Design and Methods. Applied Social Research Methods Series. London: Sage Publications.

Zeng, S.X.; Shi, J.J. and Lou, G.X. (2007) A synergetic model for implementing an integrated management system: an empirical study in China. Journal of Cleaner Production, Vol. 15, No. 18, pp. 1760-1767. http://dx.doi.org/10.1016/j.jclepro.2006.03.007

Zutshi, A. and Sohal, A.S. (2004) Adoption and maintenance of environmental management systems: critical success factors. Management of Environmental Quality: an International Journal, Vol. 15, No. 4, pp. 399-419. http://dx.doi.org/10.1108/14777830410540144

Zutshi, A. and Sohal, A.S. (2005) Integrated management system: the experiences of three Australian Organizations. Journal of Manufacturing Technology Management, Vol. 16, No. 2, pp. 211-232.

\section{Biography}

Eduardo Guilherme Satolo is Coordinator and Professor at Polytechnic Faculty of Campinas (Policamp) and Jaguariuna Faculty (FAJ). He conducted a master research at Methodist University of Piracicaba (Unimep), Brazil, in a research project of Integrated Management System in sugar-ethanol companies. His research interests include production management, quality management and production planning and control and integrated management system.

Contact: egsatolo@unimep.br

Felipe Araujo Calarge is currently Professor at Industrial Engineering Post Graduation Program of Universidade Nove de Julho (UNINOVE) and at Technical School of State University of Campinas (CTC/UNICAMP). He conducted a postdoctoral research at Universidad Complutense de Madrid in Spain, working in a research project related with Lean Manufacturing approaches in Brazilian and Spanish companies. His research interests include continuous improvement processes, Integrated Management Systems, management and costing in environmental systems.

Contact: fcalarge@uninove.br

Paulo Augusto Cauchick Miguel obtained his PhD in Manufacturing Engineering from the School of Manufacturing and Mechanical Engineering at the University of Birmingham, UK. His industrial experience in Brazil includes working as a manufacturing engineer for Varga/TRW and Bendix/Allied automotive brake system companies. He is currently an Adjunct Professor at the Department of Production and Systems Engineering of the Federal University of Santa Catarina (UFSC) in Brazil 
and an Associate Editor of Revista Produção. He has also served as the Editor of Brazilian Journal of Operations and Production Management from 2004 to 2008. His primary research interests are in the areas of product development management, project management, and quality and environmental systems.

Contact: cauchick@deps.ufsc.br

\section{Article Info:}

Received: August, 2012

Accepted: October, 2012 